\title{
The isolated buck boost de to de converter with high efficiency for higher input voltages
}

\author{
Satish. Bandaru, M.Tech, Project Associative \\ R. Suresh, Assistant Professor, SVEC-Suryapet, Nalgonda District, A.P.
}

\begin{abstract}
An isolated buck-boost dc/dc converter for wide input-voltage range is proposed in this paper, and the full-bridge (FB) boost converter, being one of the typical topologies, is analyzed. Due to the existence of the resonant inductor (including the leakage inductor), the FB-boost converter can only adopt the two-edgemodulation (TEM) scheme with the FB cell being leading-edge modulated and the boost cell being trailing-edge modulated to minimize the inductor current ripple over the input-voltage range, and a phase-shift-controlscheme-based TEM with the use of the market available controller IC such as UC3895 is pro-posed, which realizes phase-shifted control for the FB cell to achieve zero-voltage switching. In order to improve the reliability and efficiency of the FB-boost converter, a three-mode dual-frequency control scheme is proposed, in which the FBboost converter operates in boost, FB-boost and FB modes in low, medium and high input voltage regions, respectively, and for which the expression of the inductor current ripple is derived in this paper. As the input voltage in the FB-boost mode is close to the output voltage, the inductor current ripple in this mode is much smaller than that in the other modes, and the switching frequency of the boost cell in this mode can be lowered to one- $(2 N+1)$ th of the preset switching frequency to reduce the switching loss, and hence, to improve the efficiency. A 250-500 V input, $360 \mathrm{~V}$ output, and $6 \mathrm{~kW}$ rated power prototype is fabricated to verify the effectiveness of the design and control method. The average efficiency over the input-voltage range is $96.5 \%$, and the highest efficiency attained is $97.2 \%$.
\end{abstract}

Key words- buck, boost,, buck-boost, Isolated buck-boost converter, full-bridge boost converter, inductor current ripple,pulse width modulation(PWM), two-edge modulation (TEM), hysteresis modulation .

\section{Introduction}

The use of renewable energy has recently received worldwide attention in view of the continuous growth in energy consumption and the pressing need for reducing carbon emission to the atmosphere [1], [2]. Photovoltaic (PV) power has been a promising renewable energy source due to its zero pollution (both air and noise), ability to operate with much less restriction on location, and ease of maintenance [3]. Nowadays, the grid-connected PV system has become an important means of PV power utilization [4]-[8].

The grid-connected inverter, being an essential part of the grid-connected PV system, has profound impact on the overall efficiency and cost of the system. Currently, the most popular configuration of the twostage grid-connected inverter is a cascade configuration consisting of a front-end $\mathrm{dc} / \mathrm{dc}$ converter and a downstream inverter. The front-end $\mathrm{dc} / \mathrm{dc}$ converter performs two major tasks: 1) to produce voltage at appropriate level to the downstream inverter; 2) to extract maximum power from the PV arrays. The downstream inverter then converts the dc output voltage of the front-end $\mathrm{dc} / \mathrm{dc}$ converter into the ac grid connected voltage [9] To improve safety and provide better protection of the system, the grid-connected inverter requires galvanic isolation, which can be achieved by either inserting a line-frequency (LF) transformer in the downstream side or incorporating a high-frequency (HF) transformer in the front-end $\mathrm{dc} / \mathrm{dc}$ converter. Specifically, an LF transformer can be inserted between the output of the downstream inverter and the utility grid, or an isolated $\mathrm{dc} / \mathrm{dc}$ converter with $\mathrm{HF}$ transformer can be used as the front-end $\mathrm{dc} / \mathrm{dc}$ converter. Obviously, comparing the two isolation approaches, the use of HF transformer would result in much smaller size and weight. Thus, the HF approach for isolation is more attractive than the LF approach, especially for the low and medium power ranges

It is well known that the output voltage of PV arrays fluctuates with the output current and climate conditions such as solar radiation and ambient temperature. In other words, the output voltage of PV arrays has a wide variation range. It is thus imperative for the front-end dc/dc converter to achieve a high efficiency over the entire input-voltage range. For non isolated low- and medium-power applications, the buck, boost, cuk, and buck-boost topologies can be employed as the front-end dc/dc converter. It is known that the buck converter has the ability of voltage step down, and the efficiency decreases with increasing input voltage, whereas the boost converter has the ability of voltage step up, and the efficiency increases with increasing input voltage. Thus, the buck and boost converters are not flexible in terms of voltage range, and cannot achieve a high efficiency over a wide input-voltage range. While the cuk and buck-boost converters have the ability of voltage step up and down, the efficiencies are still lower because of the increased components' stresses. None of them satisfies the requirements for grid connection. Combining the advantages of the buck and boost converters, a two-switch buck-boost (TSBB) converter. as shown in Fig. 1, has been proposed. The TSBB converter is a simplified 
cascade connection of the buck and boost converters, and it has the ability of voltage step up and step down. Compared to the basic converters, e.g., inverting buck-boost, Cuk, Zeta, and Sepic converters, the TSBB converter features lower voltage stress of the power devices, fewer passive components, and positive output voltage, and has been used as the front-end $\mathrm{dc} / \mathrm{dc}$ converter in the grid-connected inverter.

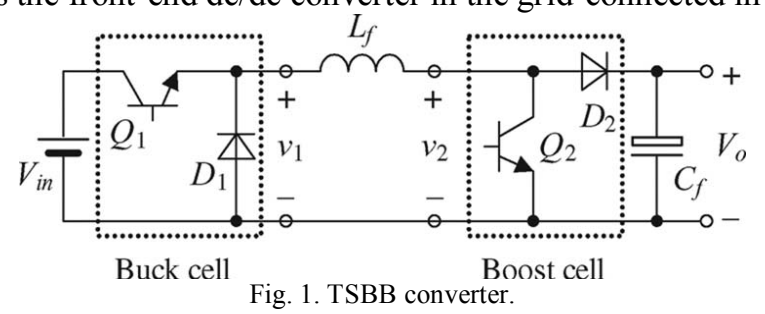

If the active switches $Q 1$ and $Q 2$ of the TSBB converter are switched ON and OFF simultaneously, the operating principle is the same as the inverting buck-boost converter, and the efficiency is relatively low due to high conduction loss and switching loss. In fact, $Q 1$ and $Q 2$ can be controlled independently. As seen in Fig. 1, by neglecting the ripple of the inductor current $i L f$, the average inductor current $I L f$ equals to $I o /(1-d 2)$, where $I o$ is the output current, and $d 2$ is duty cycle of $Q 2$. Therefore, reducing $d 2$ will reduce $I L f$, as a result, the conduction losses in the inductor and power switches are reduced. Thus, $d 2$ should be as small as possible. The voltage conversion of the TSBB converter is $V o / V \mathrm{in}=d 1 /(1-d 2)$, where $d 1$ is duty cycle of $Q 1$. It can be obtained from the voltage conversion that larger $d 1$ means smaller $d 2$. When the input voltage is higher than the output voltage, $Q 2$ can be always off, i.e., $d 2=0$, and the duty cycle of $Q 1$ is controlled to regulate the output voltage. In this case, the TSBB converter is equivalent to a buck converter, and is said to operate in the buck mode. When the input voltage is lower than the output voltage, $d 1$ is set to its maximum value, i.e., $d 1=1$, thus $d 2$ also gets its smallest value. Thus, $Q 1$ is always on, and the duty cycle of $Q 2$ is controlled to regulate the output voltage. In this case, the TSBB converter is equivalent to a boost converter, and is said to operate in the boost mode. Such a control scheme is called two-mode control scheme. In the buck mode or boost mode, only one of the two switches operates at HF, and the other one is always on or off. Thus, the total switching loss is lower than the case where both switches operate at HF. In summary, the two-mode control scheme can reduce the conduction loss and switching loss effectively, thus raising the efficiency.

Due to the fluctuation of the input voltage, the operating modes of the TSBB converter will be switched frequently when the input voltage is close to the output voltage. In order to avoid frequent modes switching, a hysteresis operation is implemented in the region where the input voltage is close to the output voltage. However, the two-mode control scheme cannot keep the output voltage stable when the input voltage enters the hysteresis. A third operation mode, namely, the buck-boost mode, is introduced when the input voltage is near the output voltage, giving rise to the three-mode control scheme. In the buck-boost mode, $d 1$ is set to a fixed large value to try to make $d 2$ be small, e.g., $d 1$ is set to 0.85 . Since both switches operate at HF, the resulting higher switching loss will reduce the efficiency. Fortunately, the input voltage is very close to the output voltage in the buck-boost mode. Thus, $d 2$ is very small, and the time for charging the inductor $L f$ is very short, leading to a very small inductor current ripple. Thus, the switching frequency can be lowered to reduce the switching loss when the converter operates in this mode.

A family of isolated buck-boost converters for wide input voltage range is derived in this paper. These converters can serve as the front-end dc/dc converter for achieving HF galvanic isolation in the grid-connected inverter, as explained earlier. The full-bridge (FB) boost converter, being a typical topology of the proposed family of converters, is analyzed, and the corresponding control scheme is proposed to achieve high efficiency over the entire input-voltage range.

This paper is organized as follows. A family of isolated buck- boost converter is derived including the FB-boost converter in Section 2. The voltage conversion of the FB-boost converter is discussed in Section 3. Section 4 proposes a two-edge modulation (TEM) scheme based on phase-shift control to minimize the inductor current ripple. In order to reduce the average current of the inductor, a two-mode control scheme for the FBboost converter is proposed in Section 5. Based on the two-mode control scheme, the selection of the turns-ratio of the transformer for minimizing the inductor current ripple over the input-voltage range is discussed in Section 6. In order to improve reliability and efficiency of the FB-boost converter, a three-mode dual frequency control scheme is proposed in Section 7. In order to explain the characteristics of FB-boost converter clearly, the comparison between non isolated buck-boost converter and FB boost converter is discussed in Section 8 . Section 9 presents the experimental results from a prototype, which is designed for an input-voltage range of 250-500 V, and output of $360 \mathrm{~V}$ and 16.67 A. Finally, conclusions are given in Section 10. 


\section{Derivation Of Isolated Buck-Boost Dc/Dc Converters}

In the TSBB converter shown in Fig. 1, $Q 1$ and $D 1$ form the buck cell, and $Q 2$ and $D 2$ form the boost cell. Galvanic isolation can be realized by inserting an HF transformer into the TSBB converter, either in the buck cell or the boost cell, leading to the buck-derived isolated cell or the boost-derived isolated cell, respectively. Fig. 2 shows four buck-derived isolated cells, i.e., forward, push-pull, half-bridge (HB), and FB cells. The forward cell can also be dual-transistor or active clamp type. Fig. 3 shows three boost-derived isolated cells, i.e., push-pull, HB, and FB cells. It should be noted that the inductor $L f$ in Fig. 1 is split into two inductors, $L f 1$ and $L f 2$, in the HB-boost cell shown in Fig. 3(b), and the input voltage of the HB-boost cell now becomes $v 1$, instead of $v 2$. Replacing the buck cell in Fig. 1 by the buck-derived isolated cells in Fig. 2, a family of isolated buck-boost converters is obtained, as shown in Fig. 4(a)-(d). Likewise, replacing the boost cell in Fig. 1 by the boost-derived isolated cells in Fig. 3, a family of isolated buck-boost converters are obtained, as shown in Fig. 4(e)-(g).

Fig. 4(d) shows the isolated buck-boost dc/dc converter, which is obtained by replacing the buck cell with the FB cell. This converter is called $F B$-boost converter

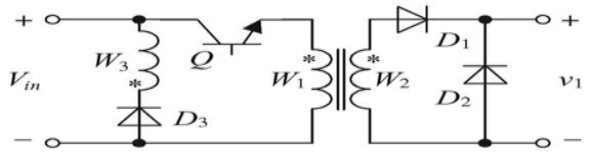

(a)

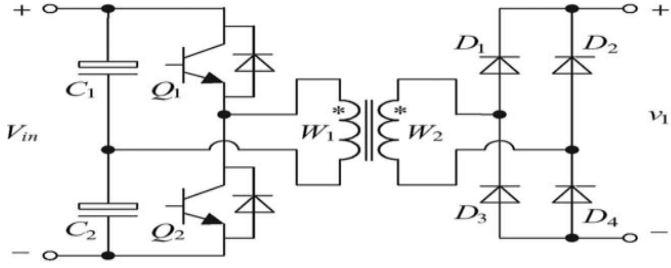

(c)

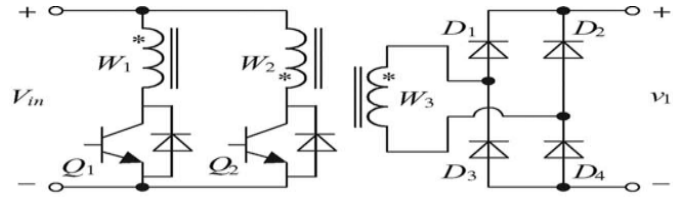

(b)

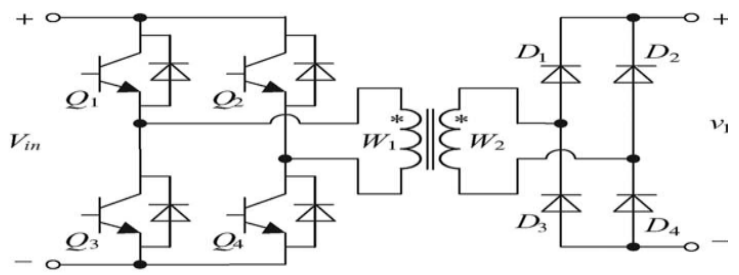

(d)

Fig. 2. Buck-derived isolated cells. (a) Forward cell. (b) Push-pull cell. (c) HB cell. (d) FB cell.

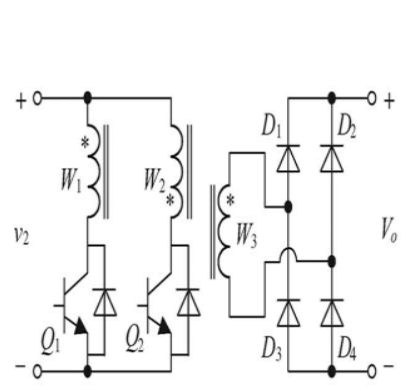

(a)

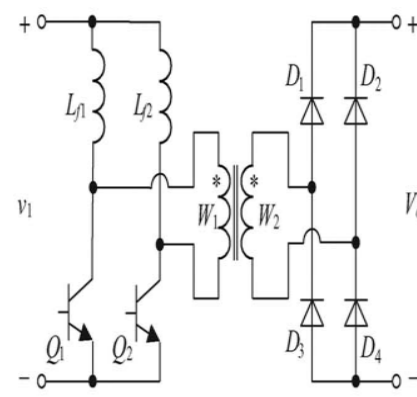

(b)

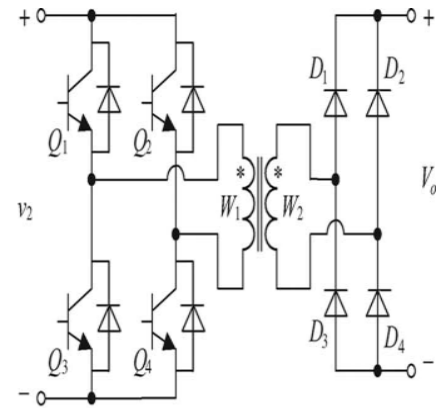

(c)

Fig. 3. Boost-derived isolated cells. (a) Push-pull cell. (b) HB cell. (c) FB cell.

In Fig. 4(d), the body diodes and junction capacitors of power switches $Q 1$ to $Q 4$ are omitted for brevity, and $L r$ is the resonant inductor which includes the leakage inductor of the transformer to achieve zero voltage switching (ZVS) for the power switches in the FB cell. It should be noted that if the resonant inductor is removed and the leakage inductor of the transformer is zero, the control strategy for the TSBB converter is effective for the FB boost converter, and the characteristics of the FB-boost converter are the same as the TSBB converter except for the turns-ratio of the transformer. However, the leakage of the transformer is inevitable in the practical circuits, and for the FB converter, an external resonant inductor is added in series with the primary of the transformer to achieve ZVS for the power switches generally.

\section{Voltage Conversion Of Fb-Boost Converter}

Due to the presence of the resonant inductor $L r$ in the FB cell, the actual duty cycle of $v 1$ is smaller than the duty cycle of $v A B$. This is the phenomenon of duty-cycle loss, which can be expressed as

$\mathrm{D}_{\text {loss }}=4 \mathrm{~kL}_{\mathrm{r}} \mathrm{I}_{\mathrm{Lf}-\mathrm{av}} \mathrm{f}_{\mathrm{s}} / \mathrm{V}_{\text {in }}$ 
Where $I L f$ av is the average current of inductor $L f, k$ is the turns ratio of the secondary to primary windings of the transformer, and $f s$ is the switching frequency of the FB cell. As shown in Fig. 4(d), the inductor current, iLf , flows into the load through diode $D b$ only when $Q b$ is switched off. Thus, the average inductor current is

$\mathrm{I}_{\text {Lf_av }}=\frac{I_{0}}{1-d_{2}}$

Where $I_{o}$ is the output current, and $d_{2}$ is the duty cycle of $Q_{b}$. Substitution of (2) into (1) gives

$D_{\text {Loss }}=\frac{4 k L_{0} I_{0} f_{s}}{V_{i n}\left(1-d_{2}\right)}$

Also, the average voltages at the two terminals of the inductor $L f$ are

$\overline{v_{1}}=\left(d_{1}-D_{\text {loss }}\right) k \mathrm{~V}_{\text {in }}=d_{1 \_ \text {eff }} k \mathrm{~V}_{\text {in }}$

$\overline{v_{2}}=\left(1-d_{2}\right) V_{0}$
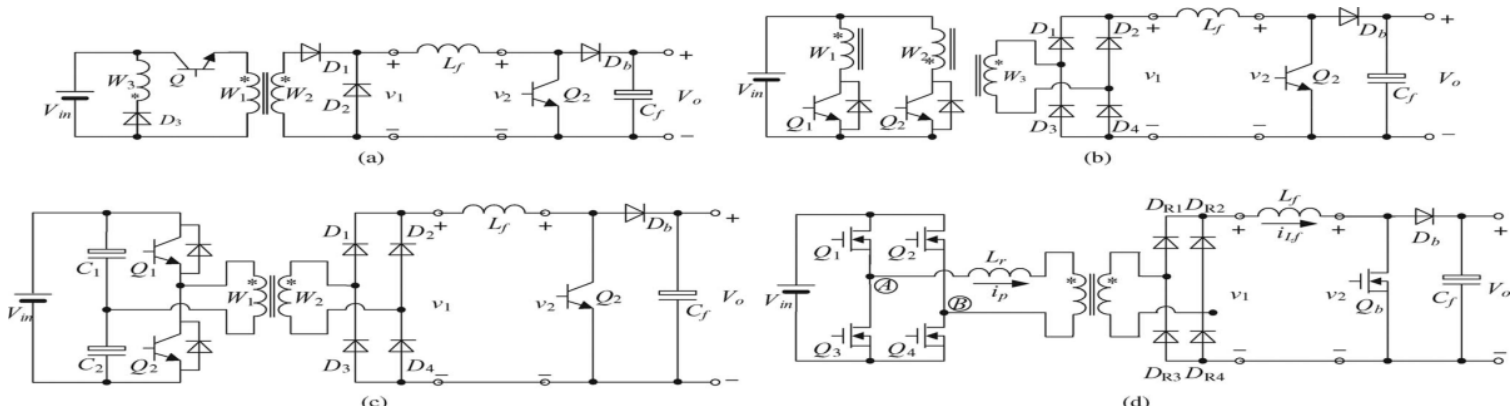

(c)

(d)
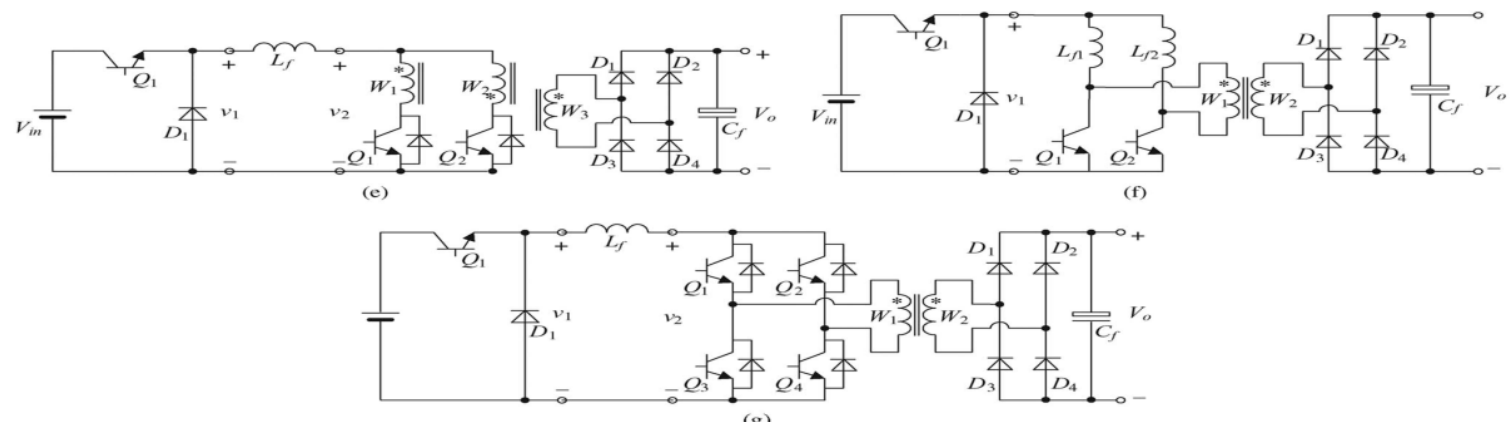

Fig. 4. Isolated buck-boost converters. (a) Forward-boost. (b) Push-pull-boost. (c) HB-boost. (d) FB-boost. (e) Buck-push-pull. (f) BuckHB. (g) Buck-FB.

Where $d_{1}$ is the duty cycle of the FB cell, i.e., the duty cycle of $v_{A B}, d_{1}$ eff $=d_{1}-D_{\text {loss }}$ is the effective duty cycle of the FB cell, i.e., the duty cycle of $v 1$.

The pulsating frequency of the voltage $v_{1}$ is $2 f_{s}$, and the pulsating frequency of $v_{2}$ is the switching frequency of $Q_{b}$, which is denoted as $f_{s b}$. Setting $f_{s b}=2 f_{s}$ would optimize the design of $L_{f}$. In the following discussion, it is assumed that $f_{s} b=2 f_{s}$. At steady state, the volt-second product of $L_{f}$ is zero in every switching period of $Q_{b}$, implying that the average voltages at the two terminals of $L_{f}$ are equal, i.e.,

$\overline{v_{1}}=\overline{v_{2}}$.

By substituting (3), (4), and (5) into (6), the expression of the output voltage is derived as

$V_{0}=\frac{d_{1-\varepsilon f f}}{1-\dot{d}_{2}} k V_{\text {in }}=\frac{d_{1}}{1-d_{2}} k V_{i n}-\frac{4 k^{2} L_{r} I_{0} f_{s}}{1-d_{2}}$

It can be seen from (7) that the output voltage of the FB-boost converter is not only related to the duty cycles of the FB cell and boost cell, but also related to the output current, the resonant inductor and the switching frequency. 


\section{Phase-Shift Tem To Minimize The Inductor Current Ripple}

In order to reduce the inductor current ripple, and hence, increase the efficiency of the TSBB converter, a TEM (TEM) has been proposed. Under the TEM scheme, the buck cell is trailing-edge modulated, and the boost cell is leading edge modulated. Alternatively, the buck cell is leading-edge modulated, and the boost cell is trailing-edge modulated. TEM can be applied to the FB-boost converter if the duty-cycle loss $D$ loss is zero. However, even no external resonance is introduced for the purpose of achieving soft-switching; the leakage inductor of the transformer is inevitable, resulting in nonzero duty-cycle loss. This duty-cycle loss results in different operation of the FB cell from the buck cell in TSBB converter. Fig. 5 shows the key waveforms of the FB-boost converter, where $Q_{1}$ and $Q_{4}$ and $Q_{2}$ and $Q_{3}$ denote the simultaneous conduction of the diagonal switches $Q_{1}$ and $Q_{4}$, and $Q_{2}$ and $Q_{3}$, respectively, irrespective of the control being a phase-shift one or a traditional one (i.e., the diagonal switches turn on and off simultaneously). Here, if the phase-shift control is adopted for the FB cell, $Q_{1}$ and $Q_{3}$ are the leading switches, and $Q_{2}$ and $Q_{4}$ are the lagging switches.

As shown in Fig. 5(a), the FB cell is trailing-edge modulated, and the boost cell is leading-edge modulated. It can be observed that the leading edge of $v 1$ does not appear at $t=0$ due to the Non zero $D_{\text {loss }}$, as shown in the hatched area. Also, the waveform of $i L f$ is shown as the solid line. If $D_{\text {loss }}=0$, the waveform of $v 1$ will move backward with its leading edge at $t=0$, and the waveform of $i L f$ is shown as the dashed line. Note that the change of the dc component of the inductor current is omitted. The overlapping conduction time of the diagonal switches of the FB cell and $Q b$ increases due to nonzero $D_{\text {loss }}$, resulting in increased inductor current ripple, compared with the case when $D_{\text {loss }}=0$.

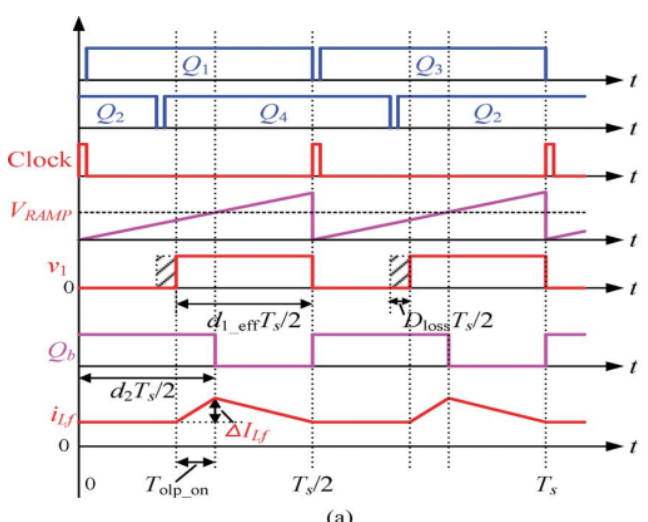

Fig. 6. PS-TEM for FB-boost converter.

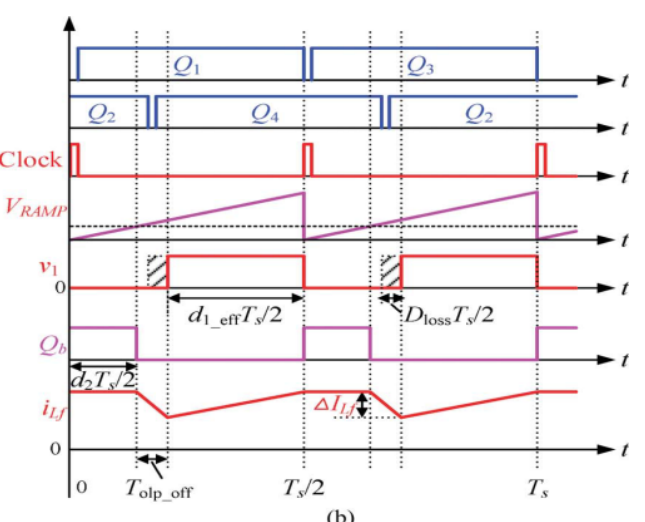

b) $k$ in $>V_{O}$.

\section{Two-Mode Ps-Tem Control Scheme}

\section{A. Derivation of Two-Mode Control Scheme}

The conduction loss of the power switches and diodes is relevant to the inductor current. Since the ripple in the inductor current is relatively smaller than the average inductor current, reducing the average inductor current leads to reduced conduction loss in the power switches and diodes as well as the inductor itself. It can be seen from (2) that in order to reduce the average inductor current, $d 2$ should be as small as possible.

According to (7), larger $d 1$ eff means smaller $d 2$. When $k V$ in $\leq V o, d 1$ eff $+d 2 \geq 1$. Due to the nonzero $D$ loss , the maximum value of $d 1$ eff is $1-D$ loss . Thus, the FB cell is set to work at full duty cycle, i.e., $d 1=1$, and the duty cycle of the boost cell, $d 2$, is controlled to regulate the output voltage, and the FB-boost converter acts as a boost converter. This operation mode is defined as the boost mode. Substituting $d 1=1$ or $d 1$ eff $=1-D$ loss into $(7)$ yields

$$
V_{o}=\frac{1-D_{\text {loss }}}{1-d_{2}} k V_{\text {in }}=\frac{k V_{\text {in }}}{1-d_{2}}-\frac{4 k^{2} L_{r} I_{o} f_{s}}{\left(1-d_{2}\right)^{2}} .
$$

When $k V$ in $>V o, d 1$ eff $+d 2<1$, i.e., $d 2<1-d 1$ eff. Two cases can be identified for this condition. In the first case, $d 2$ is greater than 0 even when $d 1$ reaches 1 in order to obtain the required output voltage. In the second case, $d 2$ can be zero and $d 1$ is controlled to regulate the output voltage. For the first case, the expression of the output voltage is the same as that shown in (11). Substituting $d 2=0$ into (11), the boundary input voltage for the two cases is

$k V_{\text {in_b }}=\frac{V_{o}}{1-D_{\text {loss }}}=V_{o}+4 k^{2} L_{r} I_{o} f_{s}$.

When $V o<k V$ in $<V o+4 k 2 L r$ Io $f_{S}, d 2$ is greater than 0 with $d 1$ being 1, the FB-boost converter operates in the boost mode, as discussed above. Thus, the input-voltage range for the boost mode is expanded from $k V$ in $<V o$ to $k V$ in $<V o+4 k 2 L r I o f s$. 
When $k V$ in $\geq V o+4 k 2 L r I o f s, d 2$ can be as small as 0 . In this case, $Q b$ of the boost cell is off, and $d 1$ is controlled to regulate the output voltage, and the FB-boost converter thus acts as an FB converter. This operating mode is defined as the $F B$ mode. Substituting $d 2=0$ into (7), we get

$V_{0}=d_{1 \_ \text {eff }} k V_{\text {in }}=d_{1} k V_{\text {in }}-4 k^{2} L_{r} I_{0} f_{s}$.

Since there are two operating modes over the input-voltage range, this control scheme is called two-mode PSTEM. Combining (11) and (13), the voltage conversion for the FB-boost converter with two-mode PS-TEM is

$V_{o}=\left\{\begin{array}{cc}\frac{k V_{\text {in }}}{1-d_{2}}-\frac{4 k^{2} L_{r} I_{0} f_{s}}{\left(1-d_{2}\right)^{2}}, & k V_{\text {in }} \leq V_{o}+4 k^{2} L_{r} I_{o} f_{s} \\ d_{1} k V_{\text {in }}-4 k^{2} L_{r} I_{0} f_{s}, & k V_{\text {in }}>V_{o}+4 k^{2} L_{r} I_{0} f_{s}\end{array}\right.$

\section{B. Comparison between Two-Mode PS-TEM and One-Mode Control}

When $k V$ in $<V o+4 k 2 L r$ Io $f s$, the FB-boost converter operates in the boost mode. According to (14), the duty cycle of the boost cell, $d 2$, can be derived as

$d_{2}=\frac{2 V_{o}-k\left(V_{\mathrm{in}}+\sqrt{V_{\mathrm{in}}^{2}-16 L_{r} V_{o} I_{o} f_{s}}\right)}{2 V_{o}}$.

Substituting (15) into (10), the expression of the inductor current ripple in the boost mode is obtained as (16) It should be noted that the expressions of the inductor current ripple are different for $k V_{\text {in }} \leq V_{o}$ and $k V$ in $>V o$, as shown in (10). Thus, the input-voltage range of the boost mode is divided into two regions, i.e., $k V_{\text {in }} \leq$ $V o$ and $V o<k V$ in $<V o+4 k 2 L r I o f_{S}$. When $k V$ in $\geq V o+4 k 2 L r I o f s$, the FB-boost converter operates in the FB mode. Substituting $d 2=0$ into (10), the expression of the inductor current ripple in the FB mode is given by

$$
\begin{aligned}
& \Delta I_{L_{f}-2 \mathrm{~m} \_\mathrm{B}}= \begin{cases}\frac{k\left(V_{o}-k V_{\text {in }}\right)\left(V_{\text {in }}+\sqrt{V_{\text {in }}^{2}-16 L_{r} V_{o} I_{o} f_{s}}\right)}{4 V_{o} L_{f} f_{s}} & k V_{\text {in }} \leq V_{o} \\
\frac{\left(k V_{\text {in }}-V_{o}\right)\left(V_{\text {in }}+\sqrt{V_{\text {in }}^{2}-16 L_{r} V_{o} I_{o} f_{s}}\right)}{4 V_{\text {in }} L_{f} f_{s}} & V_{o}<k V_{\text {in }} \leq V_{o}+4 k^{2} L_{r} I_{o} f_{s} .\end{cases} \\
& \Delta I_{L f-2 \mathrm{~m} \_F_{B}}=\frac{V_{o}\left(k V_{\text {in }}-V_{o}\right)}{2 k V_{\text {in }} f_{s} L_{f}}
\end{aligned}
$$

Combining (16) and (17), the inductor current ripple under two mode PS-TEM can be expressed as (18)

$$
\Delta I_{L_{f}-2 \mathrm{~m}}= \begin{cases}\frac{k\left(V_{o}-k V_{\mathrm{in}}\right)\left(V_{\mathrm{in}}+\sqrt{V_{\mathrm{in}}^{2}-16 L_{r} V_{o} I_{o} f_{s}}\right)}{4 V_{o} L_{f} f_{s}} & k V_{\mathrm{in}} \leq V_{o} \\ \frac{\left(k V_{\mathrm{in}}-V_{o}\right)\left(V_{\mathrm{in}}+\sqrt{V_{\mathrm{in}}^{2}-16 L_{r} V_{o} I_{o} f_{s}}\right)}{4 V_{\mathrm{in}} L_{f} f_{s}} & V_{o}<k V_{\mathrm{in}} \leq V_{o}+4 k^{2} L_{r} I_{o} f_{s} \\ \frac{V_{o}\left(k V_{\mathrm{in}}-V_{o}\right)}{2 k V_{\mathrm{in}} L_{f} f_{s}} & k V_{\mathrm{in}}>V_{o}+4 k^{2} L_{r} I_{o} f_{s} .\end{cases}
$$

The diagonal switches $Q 1$ and $Q 4$ (or $Q 2$ and $Q 3$ ) of the FB cell and $Q b$ of the boost cell can be allowed to turn on and off simultaneously. Such control is called one-mode control, and in this case, the duty cycle of the FB cell $d 1$ and the duty cycle of the boost cell $d 2$ are equal, i.e., $d 1=d 2=d$. Substituting $d 1=d 2=d$ into (7), we obtain

$V_{o}=\frac{d-D_{\text {loss }}}{1-d} k V_{\text {in }}=\frac{d}{1-d} k V_{\text {in }}-\frac{4 k^{2} L_{r} I_{o} f_{s}}{(1-d)^{2}}$

From (19), the duty cycle $d$ for the one-mode control can be derived as

$$
d=\frac{\left(k V_{\text {in }}+2 V_{o}\right)-k \sqrt{V_{\text {in }}^{2}-16 L_{r} I_{o} f_{s}\left(k V_{\text {in }}+V_{o}\right)}}{2\left(k V_{\text {in }}+V_{o}\right)}
$$


According to the operation principle of the one-mode control, the inductor current ripple in the one-mode control is

$$
\Delta I_{L f_{-} 1 \mathrm{~m}}=\frac{V_{o}(1-d)}{2 L_{f} f_{s}} .
$$

Substituting (20) into (21), the expression of the inductor current ripple in the one-mode control can be expressed as

$\Delta I_{L_{f}-1 \mathrm{~m}}=\frac{V_{o}\left(k V_{\text {in }}+k \sqrt{V_{\text {in }}^{2}-16 L_{r} I_{o} f_{s}\left(k V_{\text {in }}+V_{o}\right)}\right)}{2\left(k V_{\text {in }}+V_{o}\right) L_{f} f_{s}}$

According to (18) and (22), the inductor current ripple as a function of the input voltage under two-mode PSTEM and one-mode control can be found, as shown graphically in Fig. 7, where the input-voltage range is $250-500 \mathrm{~V}, V o=360 \mathrm{~V}, I o=16.7 \mathrm{~A}, L r=5 \mu \mathrm{H}, L f=310 \mu \mathrm{H}, f_{S}=50 \mathrm{kHz}, f_{S} b=2 f_{S}=100 \mathrm{kHz}$, and $k=1$. From Fig. 7,it can be seen that the inductor current ripple under the two-mode PS-TEM is much smaller than that under the one-mode control.

Using (15) and putting $d 2=0$ in (2), the average inductor current in the two-mode PS-TEM is derived as (23) shown at the bottom of the this page

Similarly, putting (20) into (2), the average inductor current under the one-mode control is derived as

$I_{L_{f} \_ \text {av } \_1 \mathrm{~m}}=\frac{2\left(k V_{\text {in }}+V_{o}\right) I_{o}}{k V_{\text {in }}+k \sqrt{V_{\text {in }}^{2}-16 L_{r} I_{o} f_{s}\left(k V_{\text {in }}+V_{o}\right)}}$

Substituting the parameters given above into (23) and (24), the average inductor current under two-mode PSTEM and one mode control are depicted in Fig. 8. It can be seen that the average inductor current under the twomode PS-TEM is much smaller than that under the one-mode control.

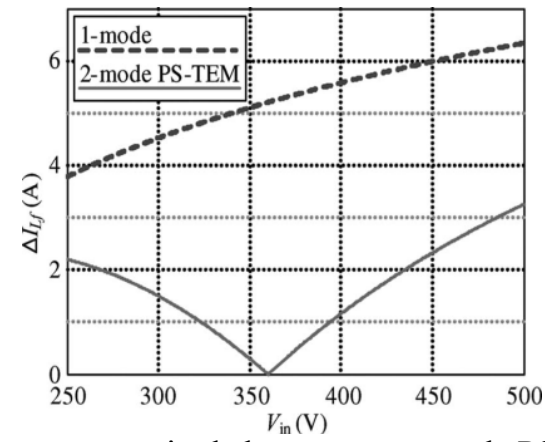

Fig. 7. Comparison of inductor current ripple between two-mode PS-TEM and one-mode control

$$
I_{L f \_\mathrm{av} \_2 \mathrm{~m}}= \begin{cases}\frac{2 V_{o} I_{o}}{k\left(V_{\mathrm{in}}+\sqrt{V_{\mathrm{in}}^{2}-16 L_{r} V_{o} I_{o} f_{s}}\right)} & \left(k V_{\mathrm{in}} \leq V_{o}+4 k^{2} L_{r} I_{o} f_{s}\right) \\ I_{o} & \left(k V_{\mathrm{in}}>V_{o}+4 k^{2} L_{r} I_{o} f_{s}\right)\end{cases}
$$

\section{Optimal Design Of Transformer Turns Ratio}

As illustrated in Sections 4 and 5, the input voltage regions for the boost mode and FB mode are related to the turns-ratio of the transformer. This section discusses the optimal design of the turns-ratio in order to minimize the inductor current ripple over the entire input-voltage range. From (18), the smaller the 


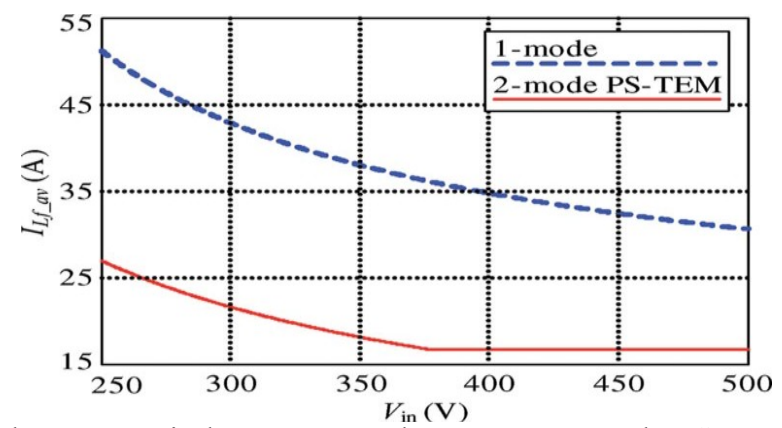

Fig. 8. Comparison of the average inductor current between two-mode PSTEM and one-mode control.

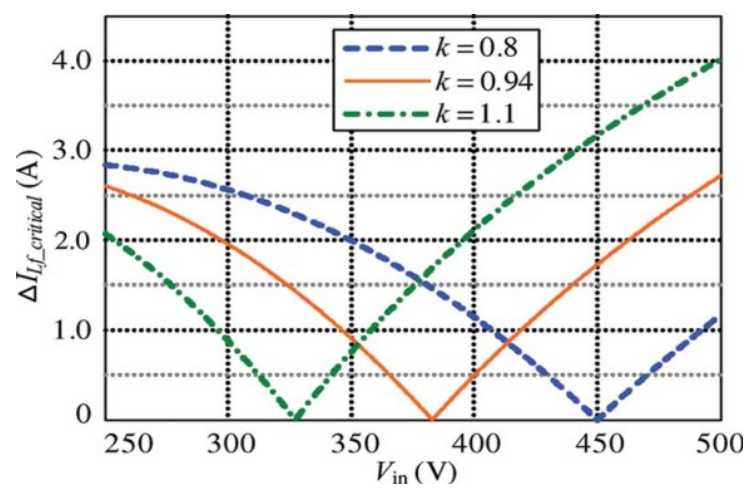

Fig. 9. Inductor current ripple under different turns ratio.

Value of $I o$, the larger the inductor current ripple. Considering the critical output current at the boundary of the continuous inductor current mode, which is designed to be $10 \%$ of full load, and substitution of $I o=0.10 \times 16.7=1.67 \mathrm{~A}$ into (18), the inductor current ripple under different turns-ratio are plotted in Fig. 9 . Here, the value of the inductor current ripple peaks at the lowest and highest input voltage. In order to achieve lowest inductor current ripple over the entire input-voltage range, the peak values at the lowest and highest input voltage should be equal, i.e.,

$$
\Delta I_{L f \_2 \mathrm{~m}}\left|V_{\text {inm in }}=\Delta I_{L f \_2 \mathrm{~m}}\right| V_{\text {inmax }}
$$

According to (18) and (25), the following expression is obtained:

$$
\frac{k\left(V_{o}-k V_{\text {inmin }}\right)\left(V_{\text {inmin }}+\sqrt{V_{\text {inmin }}^{2}-16 L_{r} V_{o} I_{o} f_{s}}\right)}{4 V_{o} L_{f} f_{s}}
$$

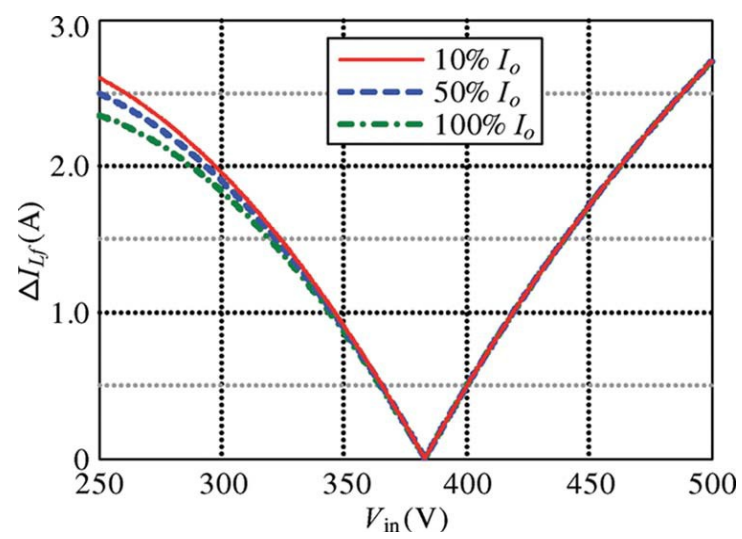

Fig. 10. Inductor current ripple at different output current when $k=0.94$. 


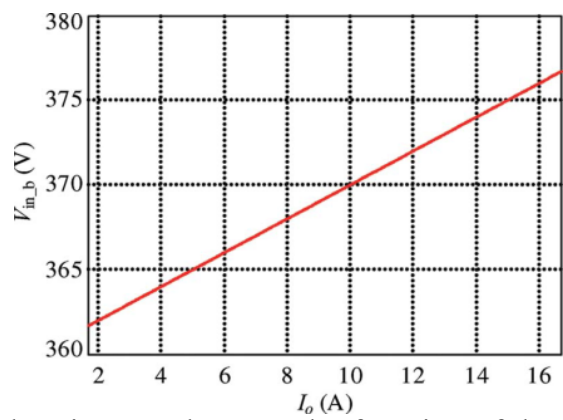

Fig. 11. Boundary input voltage as the function of the output current.

Putting $V$ inmin $=250 \mathrm{~V}, V$ inmax $=500 \mathrm{~V}$, and $I o=0.10 \times 16.7=1.67$ A (other parameters being the same as those used in Section V) in (26), we obtain $k=0.94$.

Substituting $k=0.94$ into (18), we obtain the inductor current ripple under different load conditions over the entire input voltage range, as depicted in Fig. 10. Here, we see that the peak values of the inductor current ripple at the lowest and highest input voltages are equal. In practical construction of transformer, both the primary and secondary windings are selected to be nine turns, and hence, the actual turns-ratio is 1.

\section{Three-Mode Dual-Frequency Ps-Tem Control Scheme}

\section{A. Problems of Two-Mode PS-TEM Control}

According to (12), the boundary input voltage $V$ in $\mathrm{b}$ between the FB mode and the boost mode as a function of the output current $I o$ is depicted in Fig. 11. Clearly, Vin b gets its minimum value $V_{\text {in }} b_{\min }=362 \mathrm{~V}$ at $10 \%$ full load and maximum value $V$ in $b_{\max }=376 \mathrm{~V}$ at full load. In other words, $V$ in $\mathrm{b}$ varies with $I o$, and the variation range of $V$ in $b$ is $[362 \mathrm{~V}, 376 \mathrm{~V}]$. When the input voltage falls in this region, the choice of operating mode of the FB-boost converter depends on the output current. Furthermore, even $I o$ is constant, while the input voltage fluctuates around $V \mathrm{in} \mathrm{b}$, the operating mode of the FB-boost converter will be switched frequently.

\section{B. Three-Mode PS-TEM Control}

In order to solve the problems of two-mode PS-TEM control, a third region of $\left[V_{\text {in }} b_{\min }, V_{\text {in }} b_{\max }\right]$ is introduced. In this region, the FB cell works at a fixed maximum duty cycle $d 1$ max, so that the duty cycle of the boost cell, $d 2$, is set as small as possible in order to reduce the average inductor current, and at the same time $d 2$ is controlled to regulate the output voltage. This operating mode is defined as the FB-boost mode.Therefore, the input-voltage range is divided into three regions, i.e., $V$ in $\leq V$ in $b_{\min }$ for the boost mode, $V_{\text {in }} b_{\min }<V$ in $\leq V$ in $\mathrm{b}_{\max }$ for the FB-boost mode, and $V \mathrm{in}>V \mathrm{in} \mathrm{b}_{\max }$ for the FB mode. Furthermore, the turns-ratio of the transformer has been selected as 1 . Since there are three operating modes over the input-voltage range, this control scheme is called three-mode PS-TEM.

Substituting $d 1=d 1$ max into (7), we get

$$
V_{o}=\frac{d_{1-\max }}{1-d_{2}} k V_{\text {in }}-\frac{4 k^{2} L_{r} I_{o} f_{s}}{\left(1-d_{2}\right)^{2}}
$$

As mentioned above, in the FB-boost mode, $d 1$ max should be made as large as possible to reduce $d 2$. We set the minimum value of $d 2$ as 0.05 in this paper. Substituting $V_{\text {in }} \mathrm{b}_{\max }=376 \mathrm{~V}, I o=0.10 \times 16.7=1.67 \mathrm{~A}$, and $d 2=$ 0.05 into (27) yields $d 1 \max =0.92$.

Combining (14) and (27), and substituting $k=1$ and $d 1 \max =0.92$, the voltage conversion of the FB-boost

converter under three- mode PS-TEM control is

$$
V_{o}= \begin{cases}\frac{V_{\text {in }}}{1-d_{2}}-\frac{4 L_{r} I_{o} f_{s}}{\left(1-d_{2}\right)^{2}} & V_{\text {in }} \leq 362 \mathrm{~V} \\ \frac{0.92 V_{\text {in }}}{1-d_{2}}-\frac{4 L_{r} I_{o} f_{s}}{\left(1-d_{2}\right)^{2}} & 362 \mathrm{~V}<V_{\text {in }} \leq 376 \mathrm{~V} \\ d_{1} V_{\text {in }}-4 L_{r} I_{o} f_{s} & V_{\text {in }}>376 \mathrm{~V}\end{cases}
$$

\section{Three-Mode Dual-Frequency PS-TEM Control}

According to (27), the duty cycle of the boost cell $d 2$ in the FB-boost mode can be expressed as 


$$
\begin{aligned}
& d_{2 \_ \text {FB_b }}= \\
& \frac{2 V_{o}-k\left(d_{1 \_ \text {max }} V_{\text {in }}+\sqrt{\left(d_{1 \_ \text {max }} V_{\text {in }}\right)^{2}-16 L_{r} V_{o} I_{o} f_{s}}\right)}{2 V_{o}}
\end{aligned}
$$

Substituting (29) into (10), the inductor current ripple in theFB-boost mode can be derived as (30) shown at the bottom ofthis page.

Combining (18) and (30), and using the parameters of the prototype, the inductor current ripple under threemode PS-TEM control is given in (31). According to (31), the inductor current ripple under three-mode PSTEM control can be obtained, as plotted in solid line in Fig. 12. Here, the inductor current ripple in FB-boost mode is very small, compared to the other two modes. This provides the possibility to lower the switching frequency in this mode, and hence, reduce the switching loss (31).

In practice, the switching frequency of the FB cell cannot be lowered to avoid saturation of the transformer, and only the switching frequency of the boost cell can be lowered. As seen in Fig. 6, the switching frequency of the boost cell $f_{s b}=2 f_{s}$, and the positive ( $Q_{1}$ and $Q_{4}$ conducting simultaneously) and negative ( $Q_{2}$ and $Q_{3}$ conducting simultaneously) half cycles of.

$$
\Delta I_{L_{f} \_\mathrm{FB} \_\mathrm{b}}= \begin{cases}\frac{k\left(V_{o}-k V_{\text {in }}\right)\left(d_{1-\max } V_{\text {in }}+\sqrt{\left(d_{1-\max } V_{\text {in }}\right)^{2}-16 L_{r} V_{o} I_{o} f_{s}}\right)}{4 V_{o} L_{f} f_{s},} & k V_{\text {in }} \leq V_{o} \\ \frac{\left(k V_{\text {in }}-V_{o}\right)\left(d_{1-\max } V_{\text {in }}+\sqrt{\left(d_{1-\max } V_{\text {in }}\right)^{2}-16 L_{r} V_{o} I_{o} f_{s}}\right)}{4 V_{\text {in }} L_{f} f_{s},} & k V_{\text {in }}>V_{o}\end{cases}
$$

$$
\Delta I_{L_{f}-3 \mathrm{~m}}= \begin{cases}\frac{\left(V_{o}-V_{\mathrm{in}}\right)\left(V_{\mathrm{in}}+\sqrt{V_{\mathrm{in}}^{2}-16 L_{r} V_{o} I_{o} f_{s}}\right)}{4 V_{o} f_{s} L_{f},} & V_{\mathrm{in}} \leq 360 \mathrm{~V} \\ \frac{\left(V_{\mathrm{in}}-V_{o}\right)\left(V_{\mathrm{in}}+\sqrt{V_{\mathrm{in}}^{2}-16 L_{r} V_{o} I_{o} f_{s}}\right)}{4 V_{\mathrm{in}} L_{f} f_{s},} & 360 \mathrm{~V}<V_{\mathrm{in}} \leq 362 \mathrm{~V} \\ \frac{\left(V_{\mathrm{in}}-V_{o}\right)\left(0.92 V_{\mathrm{in}}+\sqrt{\left(0.92 V_{\mathrm{in}}\right)^{2}-16 L_{r} V_{o} I_{o} f_{s}}\right)}{4 V_{\mathrm{in}} L_{f} f_{s},} & 362 \mathrm{~V}<V_{\mathrm{in}} \leq 376 \mathrm{~V} \\ \frac{V_{o}\left(V_{\mathrm{in}}-V_{o}\right)}{2 V_{\mathrm{in}} f_{s} L_{f}} & V_{\mathrm{in}}>376 \mathrm{~V} .\end{cases}
$$

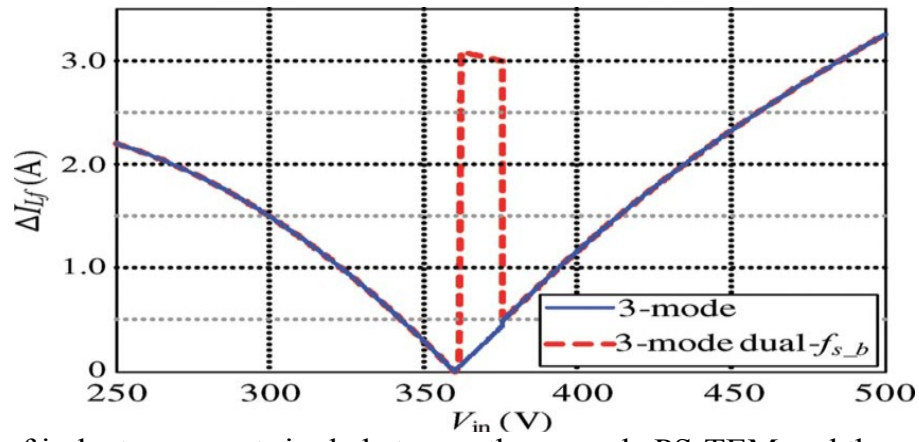

Fig. 12. Comparison of inductor current ripple between three-mode PS-TEM and three-mode dual-frequency PS-TEM control. 


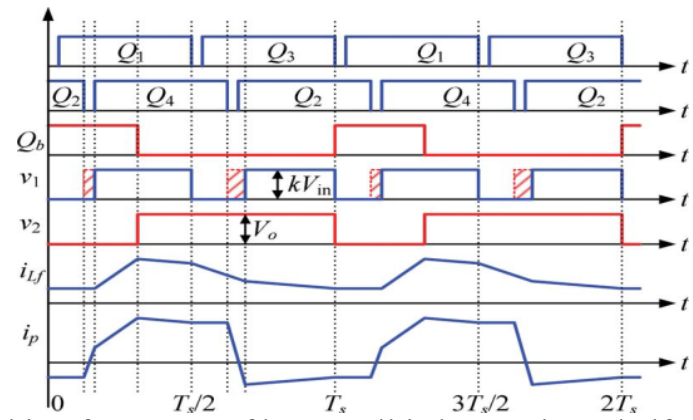

Fig. 13. Switching frequency of boost cell is lowered to a half when $k V \mathrm{in} \leq V O$

The FB cell is consistent with the operation of $Q b$. Thus, the primary current of the transformer, ip, is symmetrical, and no dc component exists in the transformer. If the switching frequency of the boost cell is reduced by half, as shown in Fig. 13, either the positive or negative half cycle (not both) of the FB cell is consistent with the operation of $Q b$ in every switching period of the boost cell. In that case, $i p$ is no longer symmetrical, and a dc component that exists in $i p$ will make the transformer saturate. Similarly, lowering the switching frequency of the boost cell by $1 /(2 N)$ will result in saturation of the transformer, where $N$ is a positive integer. In order to avoid asymmetry in the primary current, the switching frequency of the boost cell can be lowered to $1 / 3$, as shown in Fig. 14. Under this condition, the positive and negative half cycles of the FB-cell are consistent with the operation of $Q b$ in every switching period of the boost cell, and $i p$ is symmetrical in every two switching periods of the boost cell. Similarly, the switching frequency of the boost cell can be lowered to $1 /(2 N+1)$.

As shown in Fig. 14(a), when $k V$ in $\leq V o$, the inductor current ripple after lowering the switching frequency of the boost cell is also determined by the overlap ON-time Tolp on of $Q 1$ and $Q 4$ (or $Q 2$ and $Q 3$ ) of the FB cell and $Q b$ of the boost cell, which
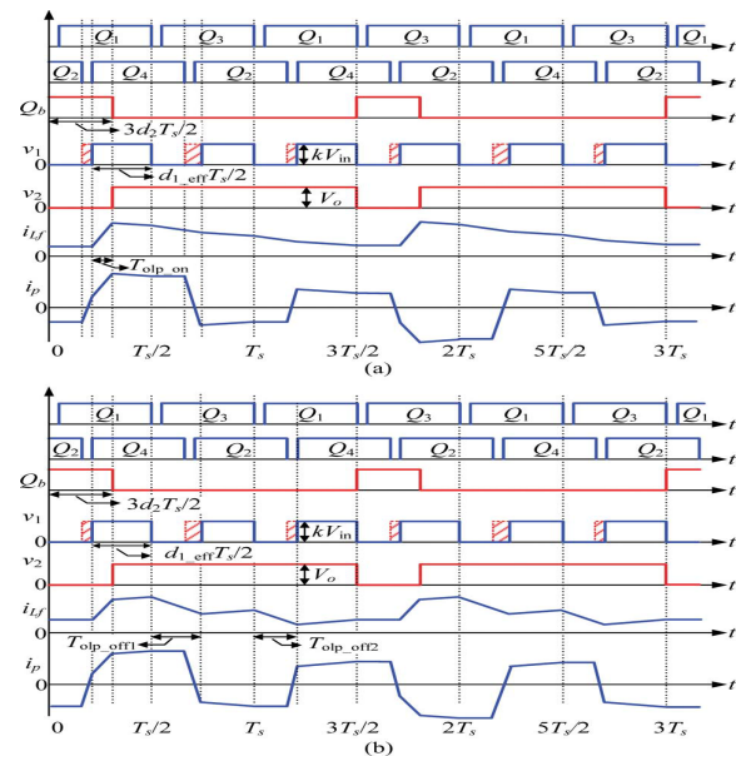

Fig. 14. Switching frequency of boost cell is lowered to $1 / 3$. (a) $k V$ in $\leq V o$. (b) $k V$ in $>V o$.

can be expressed as

$T_{\text {olp } \_ \text {on }}=d_{2} \frac{3 T_{s}}{2}-\left(1-d_{1 \_ \text {eff }}\right) \frac{T_{s}}{2}=\frac{3 d_{2}+d_{1 \_ \text {eff }}-1}{2} T_{s}$

When $k V$ in $>V o$, the inductor current ripple is determined by the overlap off time Tolp off of $Q 1$ and $Q 4$ (or $Q 2$ and $Q 3$ ) and

$Q b$, which consists of two parts, namely, Tolp off1 and Tolp off2, as shown in Fig. 14(b). Also, Tolp off can be written as

$T_{\text {olp_off }}=2\left(1-d_{1 \_ \text {eff }}\right) \frac{T_{s}}{2}=\left(1-d_{1 \_ \text {eff }}\right) T_{s}$

Substituting (32) and (33) into (8) and (9), respectively, the inductor current ripple after lowering the switching frequency of the boost cell in the FB-boost mode can be obtained as (34) as shown at the top of the next page. Using (34), we can plot the inductor current ripple after reducing the switching frequency in FB-boost mode, as 
shown by the dashed line in Fig. 12. Here, we observe that the inductor current ripple increases, but is still smaller than the maximum inductor current ripple in other modes.

$$
\Delta I_{\left.L_{f}-3 \mathrm{~m}\right\lrcorner \mathrm{f}}= \begin{cases}\frac{k V_{\text {in }}}{L_{f} f_{s}}-\frac{k\left(3 k V_{\text {in }}-V_{o}\right)\left(d_{1-\max } V_{\mathrm{in}}+\sqrt{\left(d_{1-\max } V_{\mathrm{in}}\right)^{2}-16 L_{r} V_{o} I_{o} f_{s}}\right)}{4 V_{o} L_{f} f_{s}} & k V_{\text {in }} \leq V_{o} \\ \frac{V_{o}}{L_{f} f_{s}}-\frac{V_{o}\left(d_{1-\max } V_{\text {in }}+\sqrt{\left(d_{1-\max } V_{\text {in }}\right)^{2}-16 L_{r} V_{o} I_{o} f_{s}}\right)}{2 V_{\text {in }} L_{f} f_{s}} & k V_{\text {in }}>V_{o} .\end{cases}
$$

\section{Comparison Between Nonisolated Buck-Boost Converter And Fb-Boost Converter}

Basically, the isolated buck-boost converters proposed in this paper are the extension of the TSBB converter. If the transformer is ideal without the resonant inductor (including the leakage inductor), all the characteristics of the isolated buck- boost converters are the same as the TSBB converter except for considering the turns-ratio of the transformer. However, the leakage inductor always exists in the transformer in practical circuits, and specifically, for the FB-boost converter, an external resonant inductor is added in series with the primary winding of the transformer to achieve ZVS for the power switches of the FB cell. Compared with the TSBB converter, it is the resonant inductor (including the leakage inductor) that results in the differences in the characteristics between the FB-boost converter and the TSBB converter, which are described as follows

1) For the TSBB converter shown in Fig. 1, the TEM scheme is adopted to reduce the inductor current ripple. There are two possible implementations for the TEM scheme, one is that the buck cell is trailing-edge modulated and the boost cell is leading-edge modulated, and the other is that the buck cell is leading-edge modulated and the boost cell is trailing-edge modulated. For the FB-boost converter shown in Fig. 4(d), if the FB cell is trailing-edge modulated and boost cell is leading-edge modulated, the leading edge of the voltage $v 1$ will not be at the beginning of each switching period due to the duty-cycle loss resulted by the resonant inductor. It is equivalent to moving the waveform of $v 1$ forward by a time of $D$ loss $\cdot T s / 2$. Thus, the inductor current ripple increases compared with that when the resonant inductor is zero. Therefore, the TEM scheme with the FB cell being trailing-edge modulated and boost cell being leading-edge modulated is not effective for the FB-boost converter. If the FB cell is leading-edge modulated and boost cell is trailing-edge modulated, the waveform of the voltage $v 1$ is not affected by the resonant inductor, and as a consequence, this TEM scheme is suitable for the FB-boost converter. It is well known that the phase-shift control strategy is always adopted for the FB converter with the advantage of achieving ZVS for the power switches. However, the phase-shift controllers available in the market, such as UC3875, UC3879, and UC3895, are all trailing-edge modulated, and they cannot be used directly in the FB-boost converter. By "NORing" the drive signals of the two leading switches, which are obtained from UC3895, a pulse signal with the pulse width being the dead time of the drive signals of the two leading switches, is produced. This pulse signal is used as the synchronization signal for the trailing-edge modulation control IC for the boost cell. Such arrangement realizes the TEM scheme with the FB cell being leading-edge modulated and the boost cell being trailing-edge modulated, and it also realizes phaseshift control for the FB cell to achieve ZVS for the power switches.

2) Similar to the TSBB converter, the three-mode TEM scheme can be applied for the FB-boost converter. Since the inductor current ripple is smaller in FB-boost mode than that in boost mode and FB mode, the switching frequency in FB-boost mode can be reduced to increase efficiency. However, in order to avoid the transformer saturated, the switching frequency of the FB cell cannot be reduced, and only the switching frequency of the boost cell, $f_{s} b$, can be reduced. If $f_{s} b$ is reduced to $f_{s} F B /(2 N)$, where $f_{s} F B$ is the pulsating frequency of $v 1$ in the secondary side of the transformer, and it is twice the switching frequency of the power switches of the FB cell, and $N=1,2, \ldots$, the primary current of the transformer has a dc component, which will lead to the saturation of the transformer. Therefore, in order to avoid dc component in the primary current of the transformer, $f_{s} b$ can be only lowered to $f_{s} F B /(2 N+1)$.

3) In the TSBB converter, the boundary input voltage of the buck mode and boost mode is a point, i.e., the value equals to the output voltage. For the FB-boost converter, due to the existence of the resonant inductor, the boundary input voltage of the FB mode and boost mode is not a point any longer, and it varies with the load current. Therefore, in order to ensure normal operation, a three-mode TEM scheme is proposed.

4) Due to the existence of the resonant inductor, the expression of the inductor current ripple of the FBboost converter is more complicated than the TSBB converter. 


\section{Experimental Results}

In order to verify the operating principle of the FB-boost converter and the effectiveness of the control scheme, a $250-500 \mathrm{~V}$ input, $360 \mathrm{~V}$ output, and $6 \mathrm{~kW}$ rated power prototype is fabricated.

The parameters of the prototype are listed as follows:

1) FB cell switches $Q 1-Q 4: \mathrm{SPW} 47 \mathrm{~N} 60 \mathrm{C} 3$;

2) rectifiers diodes $D R 1-D R 4$ : DSEI60 - 06 ;

3) boost cell switch $Q b$ : SPW47N60C3;

4) boost cell diode $D b:$ SDP30S120;

5) inductor $L f=310 \mu \mathrm{H}$ (NCD FEE70-3200B $* 2,23$ turns);

6) output capacitor $C f=4760 \mu \mathrm{F}(680 \mu \mathrm{F} / 450 \mathrm{~V} * 7$, electrolytic $)$;

7) resonant inductor $L r=5 \mu \mathrm{H}$ (NCD FEE42-2000B, five turns);

8) transformer turns-ratio $k=1(\mathrm{NCD}$ FEE65-2000B $* 2$, both the primary and secondary windings are nine turns);

9) $\mathrm{FB}$ cell switching frequency $f_{S}=50 \mathrm{kHz}$;

10) boost cell switching frequency $f_{s} b=100 \mathrm{kHz}$.

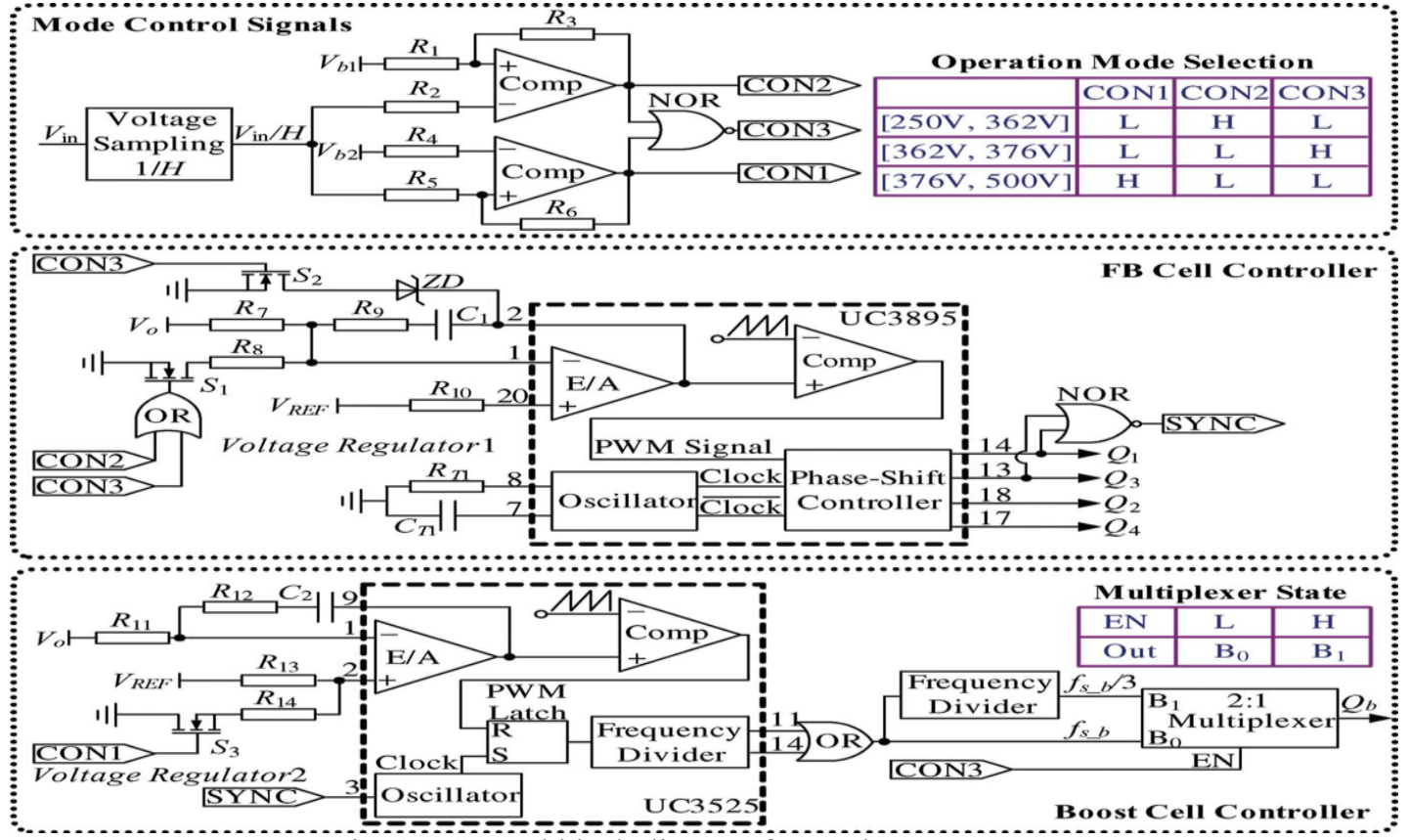

Fig. 15. Control block diagram for FB-boost converter.

Fig. 15 shows the control block diagram for the proposed control scheme. The input voltage, as obtained by the voltage sampling cell, is sent to the control block, i.e., $V$ in $/ H$, where $H$ is the sampling coefficient. Also, $\mathrm{Vb} 1$ and $\mathrm{Vb} 2$ correspond to the minimum and maximum values of the boundary input voltage divided by $H$, respectively, i.e., $V$ in $\mathrm{b}_{\min } / H$ and $V$ in $\mathrm{b}_{\max } / H$. The operating mode of the FB-boost converter can be determined by comparing $V$ in $/ H$, given $V b 1$ and $V b 2$. Furthermore, CON1, CON2 and CON3 are the operating mode selection signals corresponding to the FB mode, boost mode, and FB-boost mode, respectively. One phase-shift controller UC3895 and one pulse width-modulated (PWM) controllerUC3525 are employed for controlling the FB cell and boost cell, respectively. $Q 1$ to $Q 4$ are the drive signals from UC3895. Specifically, $Q 1$ and $Q 3$ are the drive signals for the leading switches of the FB cell, and $Q 2$ and $Q 4$ are the drive signals for the lagging switches of the FB cell. The drive signals $Q 1$ and $Q 3$ are sent to the NOR gate, giving a pulse signal with the pulse width equal to the dead time of $Q 1$ and $Q 3$. This pulse signal is then sent to the $S Y N C$ pin of UC3525 as the synchronization signal for the boost cell, thus achieving TEM for the FB-boost converter.

There are two separate output voltage regulators for the FB cell and the boost cell. In the FB mode, CON1 is at high level, and CON2 and CON3 are at low level. The signal switch $S 3$ is turned on, pulling down the voltage of the non inverting terminal of the boost-cell regulator to zero. Thus, the output of the boost-cell regulator is forced to zero, and the duty cycle $d 2$ is zero accordingly. Moreover, the FB-cell regulator determines the duty cycle of the FB cell. In the boost mode, CON2 goes high, and CON1 and CON3 go low. The signal switch $S 1$ is turned on, making the inverting terminal voltage of the FB-cell regulator to go below $V$ ref. Thus, the FB-cell regulator is saturated, and the duty cycle of the FB cell reaches its maximum value of 1 . Meanwhile, the boost-cell regulator determines the duty cycle of the boost cell. In the FB-boost mode, CON3 is 
at high level, and CON1 and CON2 are at low level. Both the switches $S 1$ and $S 2$ are turned on, and the FB-cell regulator 1 is saturated and its output voltage is clamped by the zener diode ZD through $S 2$, letting the FB cell operate at the maximum duty cycle of $d 1$ max. In addition, as CON3 is high, the switching frequency of the boost cell is selected to be one-third of $100 \mathrm{kHz}$.

Fig. 16 shows the experimental waveforms of the FB-boost converter under three-mode dual-frequency PS-TEM control, which include the primary voltage $v A B$ of the FB cell, drain to- source voltage of $Q b$ of the boost cell, $v d s Q b$, transformer primary current, ip, and inductor current $i L f$ (only ac component) from top to bottom in each figure. Fig. 16(a) shows the waveforms at $V \mathrm{in}=300 \mathrm{~V}$, with the FB-boost converter operating in the boost mode. It can be seen that the duty cycle of the FB cell is 1 , and $V o$ is regulated by controlling the duty cycle of the boost cell. Fig. 16(b) shows the waveforms at $V$ in $=365 \mathrm{~V}$, with the converter operating in the FBboost mode. The FB cell operates at a fixed maximum duty cycle of 0.92 . Since $V$ in is close to $V o$, the inductor current ripple is nearly zero. Fig. 16(c) shows the waveforms at $V$ in $=450 \mathrm{~V}$. Here, the converter operates in the FB mode, the boost cell quit working, and $V o$ is regulated by controlling the duty cycle of the FB cell. Fig. 16(d) shows the waveforms at $V \mathrm{in}=365 \mathrm{~V}$,
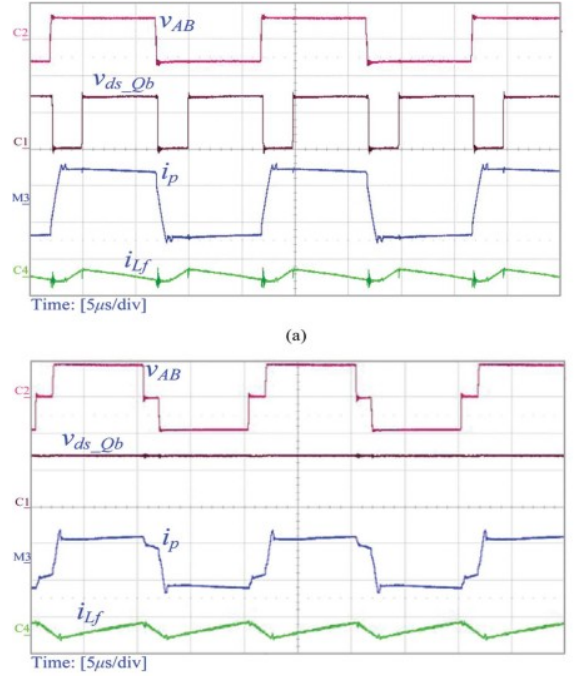

Fig. 16. Waveforms of FB-boost converter in three-mode dual-frequency PS-TEM control. (a) Boost mode. (b)

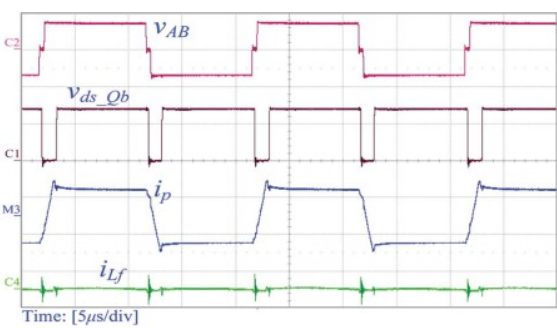

(b)

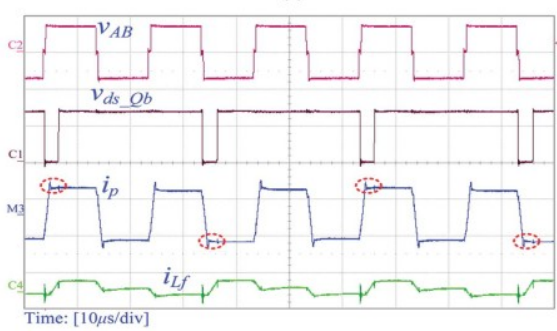

(d) FB-boost mode. (c) FB mode. (d) FB-boost mod at $33.3 \mathrm{kHz}$ ( $v A B: 500$ V/division; $v d s Q b: 250 \mathrm{~V} /$ division; ip : $20 \mathrm{~A} /$ division; $i L f: 5 \mathrm{~A} /$ division).

With the switching frequency of the boost cell lowered to $33.3 \mathrm{kHz}$, which is one-third of the preset $f_{s}$ $b$. It can be seen that the primary current of the transformer is symmetrical in every two switching periods of the boost cell.

Fig. 17 compares the measured inductor current ripples of the three-mode PS-TEM control and the three-mode dual-frequency PS-TEM control. It can be observed that the inductor current ripple after lowering the switching frequency of the boost cell in the FB-boost mode is still smaller than the maximum inductor current ripple in other modes.

Fig. 18 shows the measured efficiency under three-mode PSTEM control and three-mode dualfrequency PS-TEM control. Here, we clearly see that lowering the switching frequency of boost cell improves the efficiency

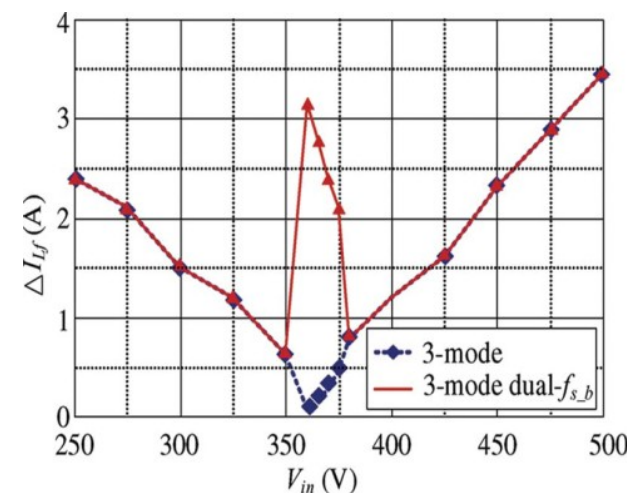

Fig. 17. Inductor current ripple of FB-boost converter. 


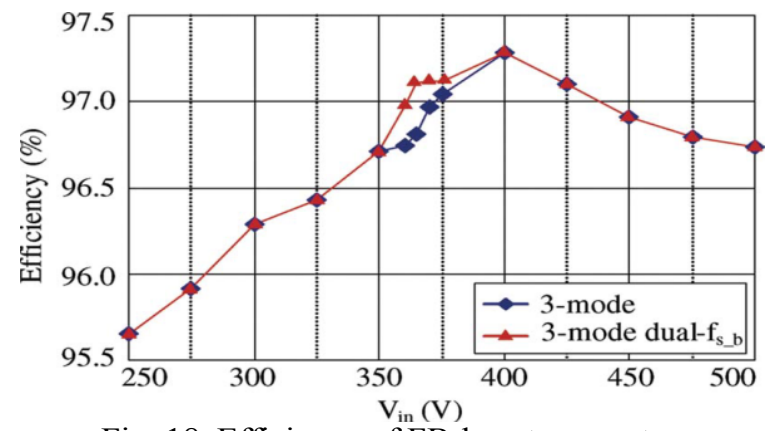

Fig. 18. Efficiency of FB-boost converter.
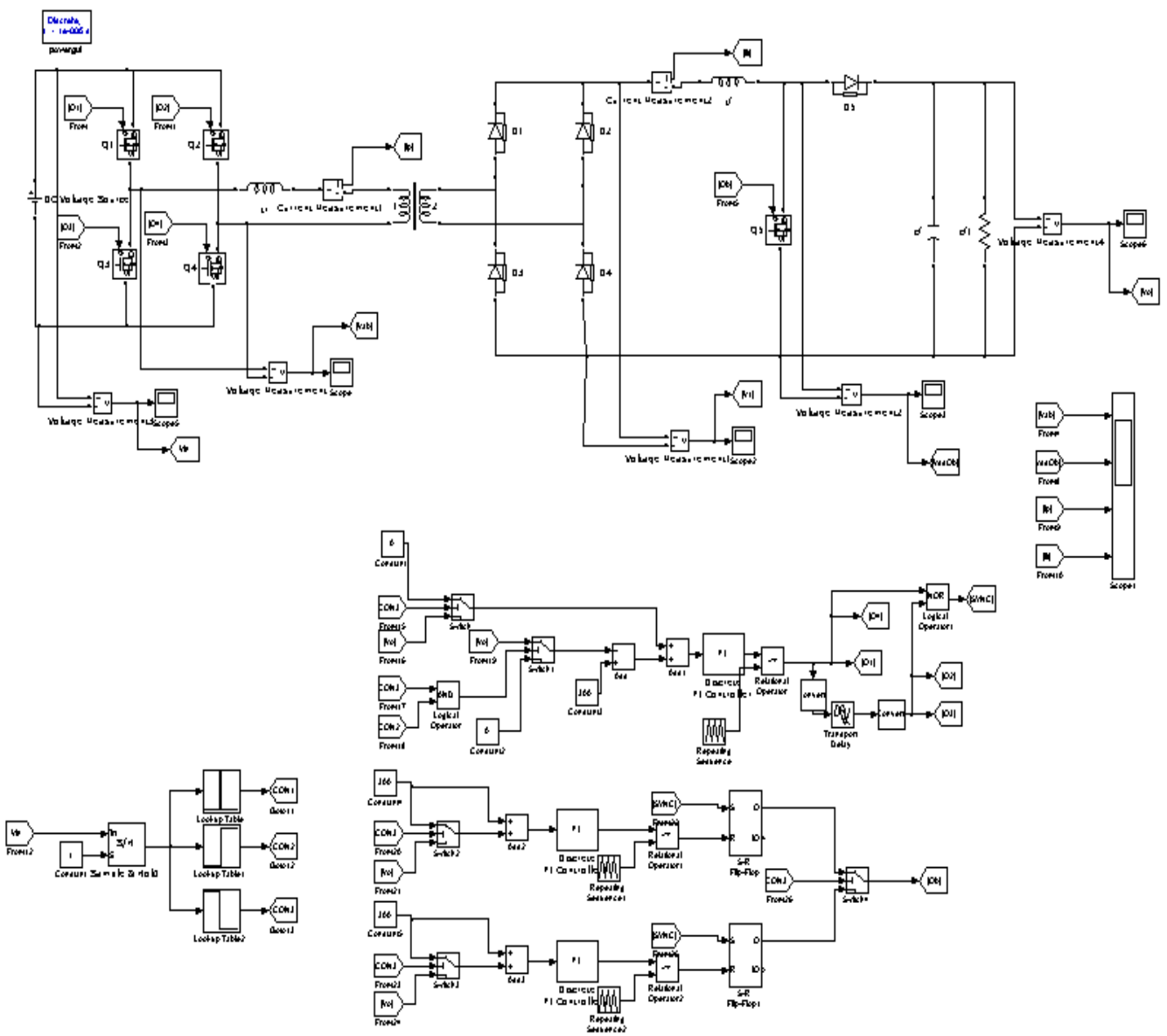

Fig.19. case study of buck-boost converter

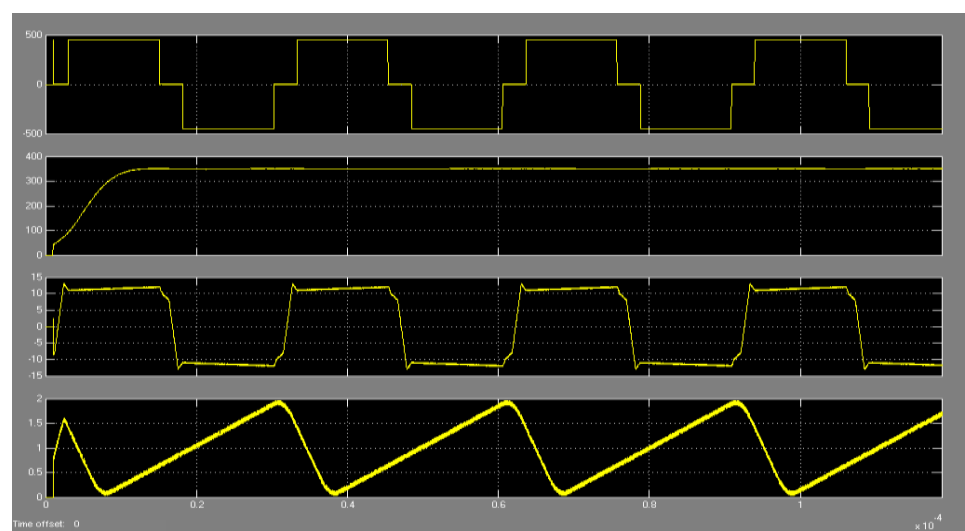

Fig. 20. Simulation output of buck boost converter 


\section{Conclusion}

A family of isolated buck-boost converters is proposed in this paper for use in applications where the input-voltage range is wide and galvanic isolation is required. For illustration, an FB boost converter version is analyzed. If the transformer is ideal, all the characteristics of the isolated buck-boost converters are the same as the TSBB converter except for considering the turns ratio of the transformer. However, the leakage inductor always exists in the transformer in practical circuits, and specifically, for the FB-boost converter, an external resonant inductor is added to achieve ZVS for the FB cell. The resonant inductor (including the leakage inductor) leads to the differences in the characteristics between the FB-boost converter and the TSBB converter. In order to minimize the inductor current ripple over the input voltage range, only the TEM scheme with FB cell being leading edge modulated and the boost cell being trailing-edge modulated can be adopted, and a phase-shift based TEM (PS-TEM) with the available controller IC such as UC3895 is proposed, which realizes phase-shift control for the FB cell. Since the boundary input voltage of the FB mode and boost mode changes with the output current due to the resonant inductor, a three-mode PSTEM control scheme is proposed to improve the efficiency and reliability, in which the converter operates in boost, FB-boost, and FB modes in the lower, medium, and higher input voltage regions respectively, and for which the expressions of the voltage conversion and the inductor current ripple are all derived. From the expression of the inductor current ripple, the inductor current ripple is much smaller than that in the other modes when the input voltage is very close to the output voltage in the FB boost mode. Thus, the switching frequency of the boost cell in this mode can be lowered to reduce the switching loss. In order to avoid saturation of the transformer, the switching frequency of the boost cell only can be reduced to one- $(2 N+1)$ th of the preset switching frequency, where $N$ is a positive integer. A $250 \mathrm{~V}-500 \mathrm{~V}$ input, $360 \mathrm{~V}$ output, and $6 \mathrm{~kW}$ rated power prototype is fabricated and tested experimentally, and the results show that the operation principle of the FB-boost converter and three mode dual-frequency PS-TEM control proposed in this paper are effective

\section{References}

[1] Xinbo Ruan, Chuan Yao, Xuehua Wang and Chi K. Tse YAO et al:: "isolated buck-boost dc/dc converters suitable for wide input-voltage range,", ieee transactions on power electronics, vol. 26, no. 9, september 2011 .

[2] P. G. Barbosa, H. A. C. Braga, M. C. B. Rodrigues, and E. C. Teixeira, "Boost current multilevel inverter and its application on single-phase grid connected photovoltaic systems," IEEE Trans. Power Electron., vol. 21, no. 4, pp. 1116-1124, Jul. 2006.

[3] T. Shimizu, O. Hashimoto, and G. Kimura, "A novel high-performance utility-interactive photovoltaic inverter system," IEEE Trans. Power Electron., vol. 18, no. 2, pp. 704-711, Mar. 2003.

[4] M. J. V. Vazquez, J. M A. Marquez, and F. S. Manzano, "A methodology for optimizing stand-alone PV-System sizing using parallel connected dc/dc converter," IEEE Trans. Ind. Electron., vol. 55, no. 7, pp. 2664- 2673, Jul. 2008.

[5] T. Kerekes, R, Teodorescu, M. Liserre, C. Klumpner, and M. Sumner, "Evaluation of three-phase transformerless photovoltaic inverter topologies," IEEE Trans. Power Electron., vol. 24, no. 9, pp. 2202-2211, Sep. 2009.

[6] F. Blaabjerg, Z. Chen, and S. B. Kjaer, "Power electronics as efficient interface in dispersed power generation systems," IEEE Trans. Power Electron., vol. 19, no. 5, pp. 1184-1194, Sep. 2004.

[7] W. Xiao, N. Ozog, and W. G. Dunford, "Topology study of photovoltaic interface formaximum power point tracking," IEEE Trans. Ind. Electron., vol. 54, no. 3, pp. 1696-1704, Jun. 2007.

[8] M. Pipattanasomporn, M. Willingham, and S. Rahman, "Implications of on-site distributed generation for commercial/ industrial facilities," IEEE Trans. Power Syst., vol. 20, no. 1, pp. 206-212, Feb. 2005.

[9] B. Yuan, X. Yang, D. Li, and Z. Wang, "A new architecture for high efficiency maximum power point tracking in grid-connected photovoltaic system," in Proc. CES/IEEE IPEMC, 2009, pp. 2117-2121.

[10] Y. C. and V. H. Wu, Y. Chen, K. Lee, and S. Shyu, "The ac line current regulation strategy for the grid-connected PV system," IEEE Trans. Power Electron., vol. 25, no. 1, pp. 209-1940, Jan. 2010. 